Article

\title{
Harmonic Analysis of Single-Phase Neutral-Point- Clamped Cascaded Inverter in Advanced Traction Power Supply System Based on the Big Triangular Carrier Equivalence Method
}

\author{
Pengcheng Han ${ }^{1}{ }^{(\mathbb{D})}$, Xiaoqiong He ${ }^{1,2, *}$, Yi Wang ${ }^{1}$, Haijun Ren ${ }^{1}$, Xu Peng ${ }^{1}$ and Zeliang Shu ${ }^{1}$ \\ 1 School of Electrical Engineering, Southwest Jiaotong University, Chengdu 611756, China; \\ birdhpc@163.com (P.H.); de_yiwang@163.com (Y.W.); haidaoren@outlook.com (H.R.); \\ pengxuswjtu@foxmail.com (X.P.); shuzeliang@swjtu.edu.cn (Z.S.) \\ 2 National Rail Transit Electrification and Automation Engineering Technique Research Center, \\ Chengdu 611756, China \\ * Correspondence: hexq@home.swjtu.edu.cn; Tel.: +86-28-6636-6863
}

Received: 17 January 2018; Accepted: 9 February 2018; Published: 14 February 2018

\begin{abstract}
An advanced traction power supply system based on a single phase neutral-point-clamped (NPC) cascaded inverter is studied. The big triangular carrier equivalence method in double coordinate system is proposed, which can reduce one coordinate system, thus simplifying the calculation. Based on the big triangular carrier equivalence method, the harmonic characteristics of a single phase NPC cascaded inverter are calculated by double Fourier transform and voltage harmonics expressions of 5-level, 9-level and 13-level output waveforms are derived. Finally, the performance and calculated results of the proposed method were verified by simulations and experiments. The result provides a theoretical basis for further studies on traction network resonance.
\end{abstract}

Keywords: advanced traction power supply system; big triangular carrier equivalence method; double Fourier transform; harmonic analysis

\section{Introduction}

Harmonics have been an important factor affecting the safe operation of railways [1-5]. In recent years, high-speed railways have developed rapidly in China and safety is the lifeline of railway transportation. The traction power supply system is the power source of railway transportation and it is important to keep the traction power supply system stable. At present, the traction power supply system of high-speed railways in China is based on single-phase $27.5 \mathrm{kV} / 50 \mathrm{~Hz} \mathrm{AC}$ feeding circuits, shown in Figure 1a. Due to the low output power quality and the existence of neutral sections in the traditional traction power supply system, the development of high-speed railway is limited. The co-phase traction power supply system has been proposed [1]. By using this system, power quality can be improved, but neutral sections between two substations still exist. To cancel the neutral sections completely, as shown in Figure 1b, the advanced traction power supply system based on power electronics converter has been proposed [2]. However, since the maximum voltage rating of existing IGBT is $6.5 \mathrm{kV}$, it cannot be used directly for $27.5 \mathrm{kV}$ traction substations. In order to promote engineering applications, the second generation advanced traction power supply system (APTSS-II) based on a single phase neutral-point-clamped (NPC) cascaded inverter is studied in this paper [3-5]. The output voltage contains high order harmonics which will cause traction network resonance. Therefore, it is necessary to study the harmonic characteristics of ATPSS-II, which will provide the reference to avoid the traction network resonance. 


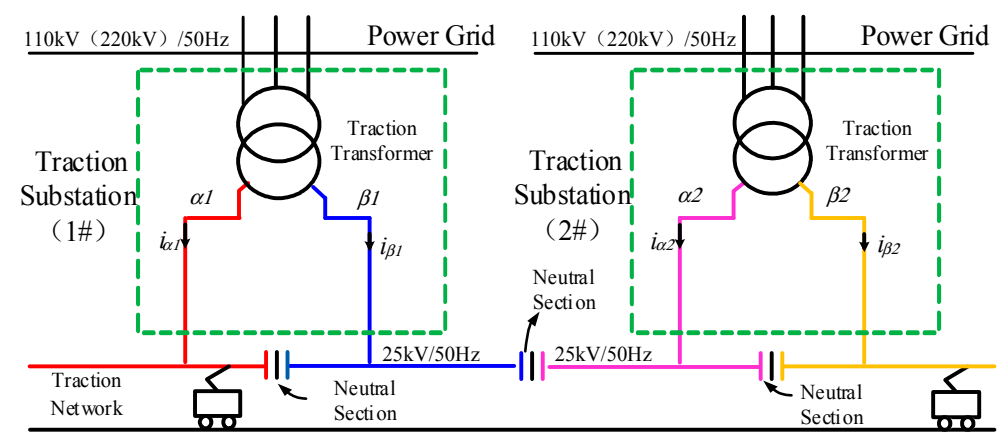

(a)

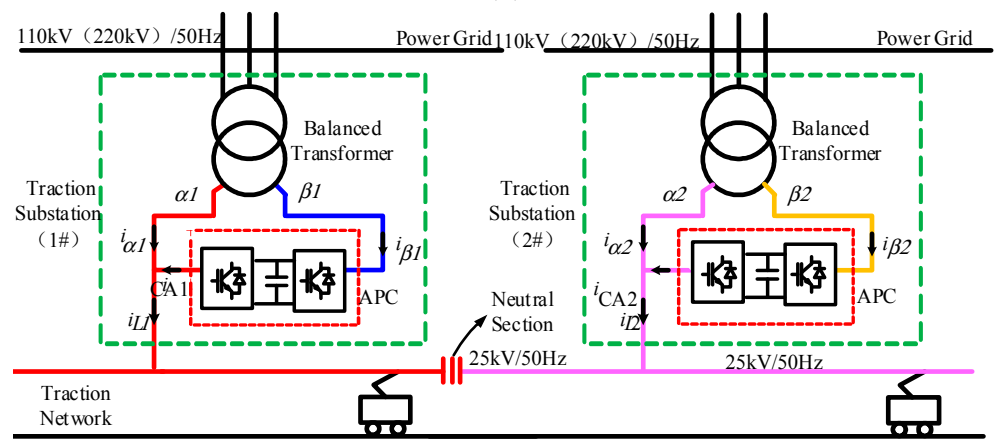

(b)



(c)

Figure 1. Traction Power Supply System. (a) Existing traction power supply system. (b) Co-phase traction power supply system. (c) Configuration of advanced traction power supply system.

The harmonic characteristics of traditional traction substations have been studied by a wide range of scholars [6-33]. The power electronic converter is non-linear, and the mathematical model is difficult to establish. The Fourier theory of jumps is analyzed in [9] and it has been applied in power electronics, though the actual equations for the jumps in the algorithms are not derived. Besides, the comparison between theoretical results and simulation or practical results is not given [10]. By contrast, the Fast Fourier Transform is a computed numerical approach method which searches the result of PWM waveform spectrum. Nevertheless, this is typically inaccurate for non-integer ratios of the carrier and modulating signal frequencies [11]. A 3-D Fourier integral has been proposed in [12-14] for output to input voltage ratio limited to 0.5 , but the construction of 3-D unit cell and mentions the limits of the Fourier integral for higher ratios are unclear. Ref. [15-17] studied the harmonic characteristic of three-phase to single-phase rectifier. However, they are not suitable for the single-phase inverter. In the case of multilevel inverter, analytical expression for multilevel PWM spectrum has been derived in [18]. However, the derivation is complicated, and the analytical solution is hard to apply. Although some scholars have been studying the harmonic characteristics of multi-level converter, research on the 
harmonic characteristic of single phase neutral-point-clamped cascaded inverter [19] could hardly be found, so it is necessary to study an efficient, simple and accurate harmonics analysis method in advanced traction power supply systems based on single phase NPC cascaded inverters.

In this paper, the advanced traction supply system based on a single phase NPC cascaded inverter is studied. According to the characteristics of the single phase NPC cascaded inverter, the big triangular carrier equivalence method in double coordinate system is proposed, which can reduce one coordinate system, thus simplifying the calculations. On the basis of the big triangular carrier equivalence method, the harmonic characteristics of a single phase NPC cascaded inverter are calculated by a double Fourier series. The performances and calculated results of the proposed method were verified with simulations and experiments.

\section{Configuration}

The configuration of ATPSS-II is shown in Figure 2. The industrial IGBT has a maximum voltage rating of $6.5 \mathrm{kV}$, while the power supply system of high-speed railways in China is based on single-phase $27.5 \mathrm{kV} / 50 \mathrm{~Hz}$ AC power supply circuits. In traditional H-bridge topology, each IGBT should have the ability to endure half of the total input voltage. Thus, the utilization of traditional $\mathrm{H}$-bridge converters in high voltage applications is rather limited. To solve this problem, multiple $\mathrm{H}$-bridge converters are connected in cascading construction to share the total input voltage. However, in high voltage applications, too much cascaded converters will add to the control complexity. In this case, cascaded NPC topology will be a better choice since each IGBT in one NPC module only needs to withstand a quarter of the input voltage, which means the number of cascaded modules will be reduced by half compared to the cascaded H-bridge topology.

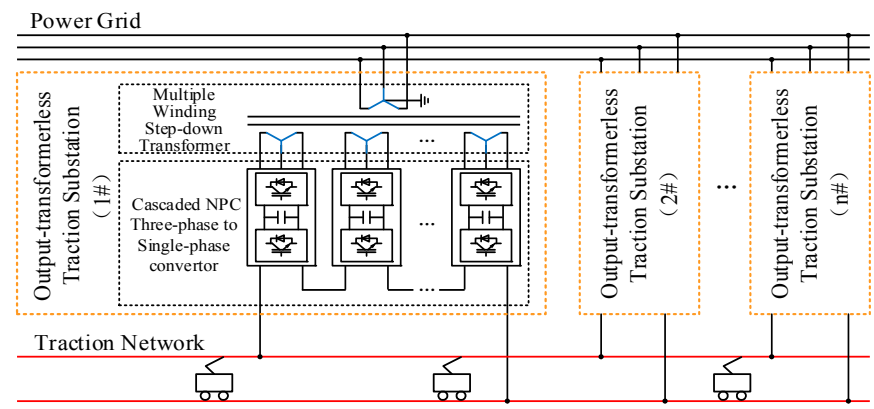

(a)

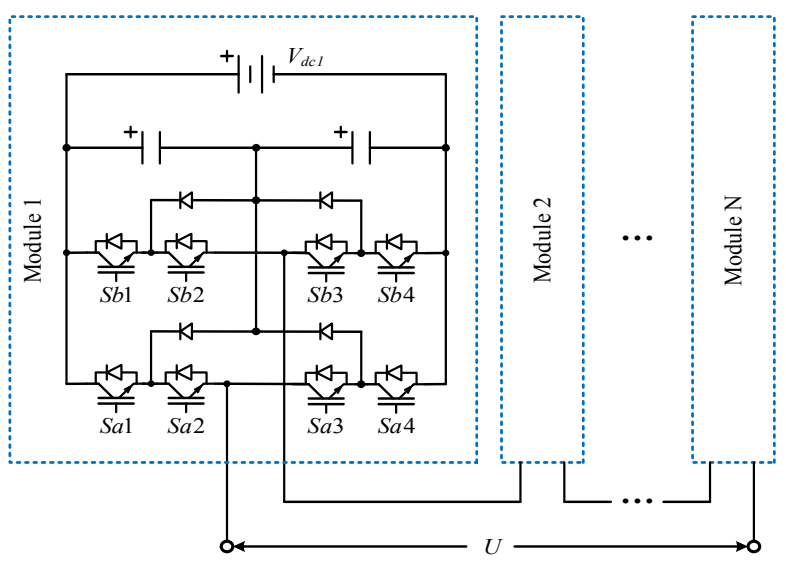

(b)

Figure 2. ATPSS-II. (a) Configuration of ATPSS-II. (b) Single-phase NPC cascaded inverter. 
The topology of a single-phase NPC-CI is shown in Figure 2b. One NPC inverter module consists of two bridge legs, while each bridge leg is composed by four IGBTs. Five voltage levels $\left( \pm V_{\mathrm{dc}}\right.$, $\pm 0.5 V_{\mathrm{dc}}, 0$ ) could be generated by nine valid switching mode combinations as listed in Table 1 , where ' 1 ' stands for on state while ' 0 ' stands for off state. Under the combination effect of $N$ cascaded modules, the NPC-CI could synthesis a staircase waveform with $4 N+1$ voltage levels, which will contribute to a better sinusoidal output voltage.

Table 1. Voltage level and switch mode.

\begin{tabular}{|c|c|c|c|c|c|c|c|c|}
\hline Level & $S_{a 1}$ & $S_{a 2}$ & $S_{a 3}$ & $S_{a 4}$ & $S_{b 1}$ & $S_{b 2}$ & $S_{b 3}$ & $S_{b 4}$ \\
\hline$V_{\mathrm{dc}}$ & 1 & 1 & 0 & 0 & 0 & 0 & 1 & 1 \\
\hline \multirow{2}{*}{$0.5 V_{\mathrm{dc}}$} & 1 & 1 & 0 & 0 & 0 & 1 & 1 & 0 \\
\hline & 0 & 1 & 1 & 0 & 0 & 0 & 1 & 1 \\
\hline \multirow{3}{*}{0} & 1 & 1 & 0 & 0 & 1 & 1 & 0 & 0 \\
\hline & 0 & 0 & 1 & 1 & 0 & 0 & 1 & 1 \\
\hline & 0 & 1 & 1 & 0 & 0 & 1 & 1 & 0 \\
\hline \multirow{2}{*}{$-0.5 V_{\mathrm{dc}}$} & 0 & 0 & 1 & 1 & 0 & 1 & 1 & 0 \\
\hline & 0 & 1 & 1 & 0 & 1 & 1 & 0 & 0 \\
\hline$-V_{\mathrm{dc}}$ & 0 & 0 & 1 & 1 & 1 & 1 & 0 & 0 \\
\hline
\end{tabular}

\section{Big Triangular Carrier Equivalence Method and Modulation of NPC Cascaded Inverter}

\subsection{Big Triangular Carrier Equivalence Method}

Because of the output uncertainty states when $S_{a 1}$ and $S_{a 4}$ are turned on simultaneously, the carrier phase shifted SPWM cannot be directly applied to single-phase NPC with load. Therefore, phase opposition disposition SPWM is applied to one leg of a NPC module. For example, phase opposition disposition SPWM can be realized in Leg a of NPC module 1 as shown in Figure 3a, in which $C_{1}$ and $C_{2}$ are triangular carriers and ua1 represents a modulation wave. The phase difference between upper carrier $C_{1}$ and lower carrier $C_{2}$ is $180^{\circ}$. Figure $3 \mathrm{~b}$ shows the carrier phase shifted with phase opposition disposition SPWM for NPC topology. The carrier of Leg $b$ can be calculated by reversing the carrier of Leg a. Through the comparison between modulation wave and carrier wave, the output of Leg a and Leg b can be calculated. As shown in Figure 3b, the output 5-level voltage can be added through the above calculation. Figure $3 \mathrm{c}$ shows big triangular carrier equivalent modulation for Leg a when it works with no-load. $C_{3}$ represents carrier for $S_{a 1}$ and $S_{a 3}$, and $C_{4}$ is the carrier for $S_{a 2}$ and $S_{a 4}$. Phase difference between $C_{3}$ and $C_{4}$ is $180^{\circ}$. Within a period of a triangle carrier, the intersections of modulation wave and two carriers are expressed as $\theta_{1}, \theta_{2}$ and $\theta_{1}{ }^{\prime}, \theta_{2}{ }^{\prime}$ in Figure $3 c$. Output level of Leg a is the sum of PWM1 and PWM2, which is precisely the same with that of phase opposition disposition SPWM waveform shown in Figure 3a.

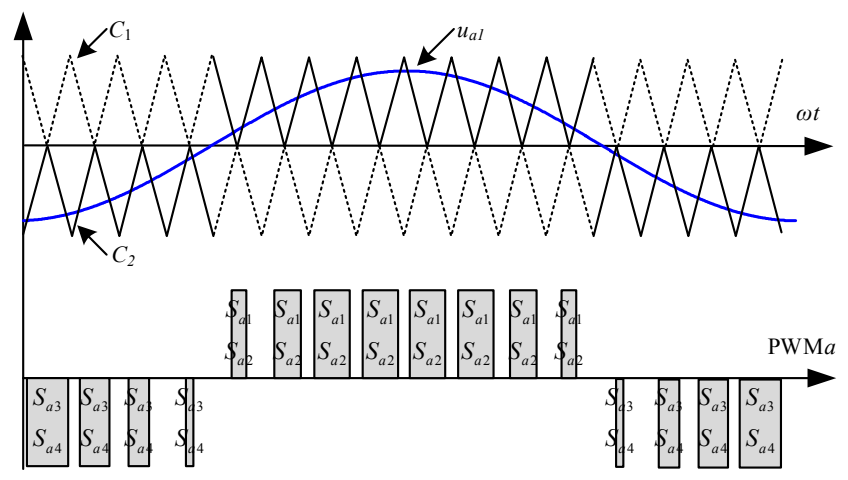

(a)

Figure 3. Cont. 




(b)

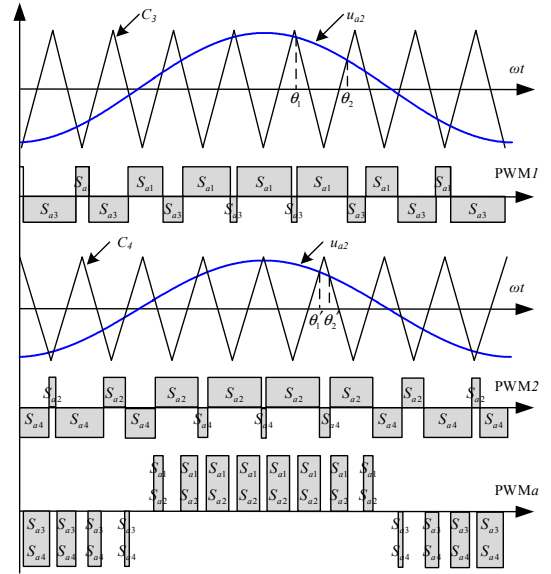

(c)

Figure 3. Modulation strategy. (a) Phase opposition disposition SPWM for one leg. (b) Carrier phase shifted with phase opposition disposition SPWM for NPC. (c) Big triangular carrier equivalence method.

\subsection{Double Coordinate System}

When phase opposition disposition SPWM is used, it is cumbersome to deduce the output spectrum with a double coordinate system. Due to the output equivalence of the big triangular carrier equivalent modulation and phase opposition disposition SPWM, the latter can be transformed to the former in the derivation process of switch function, as illustrated in Figure 3a,b.

As shown in Figure 4a,c, phase opposition disposition SPWM is taken as an example to describe the establishing process of double coordinate system. In the diagram, $\varphi$-axis is time axis. There are two layers of carriers located on both sides of $\varphi$-axis, and peak-to-peak value of the carrier is 2 . Then $\varphi$-axis is moved to the centers of two triangle carriers and redefined as $\theta_{1}$-axis and $\theta_{2}$-axis. Apparently, two individual double coordinate systems have to be established for analyzing intersections between modulation wave and two-tiered carriers of each bridge leg. It is cumbersome to deduce output spectrum with two individual double coordinate system.

There are two cases of intersections between the carrier and modulation wave, as shown in Figure 4a. In case (1), amplitude of modulation wave $\left(A_{1}\right)$ is greater than 2. $\varphi, \varphi^{\prime}$, and $\varphi^{\prime \prime}$ are defined as abscissa values of intersections between modulating signal and carrier envelope lines. Vertical ordinate values of the intersection points shown in case (1) are $2,0,-2$, then $\varphi=\arccos \left(2 / A_{1}\right)$, which is derived from $A_{1} \cos \varphi=2$. Similarly, $\varphi^{\prime}=\pi / 2, \varphi^{\prime \prime}=\arccos \left(-2 / A_{1}\right)$. In case (2), amplitude of modulation wave $\left(A_{2}\right)$ is less than 2 , and $\varphi=0, \varphi^{\prime}=\pi / 2, \varphi^{\prime \prime}=\pi$.



(a)



(b)

Figure 4. Cont. 


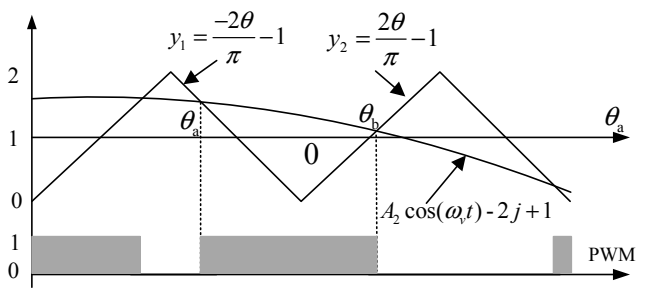

(c)

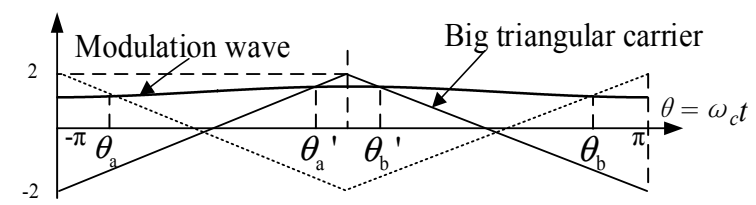

(d)

Figure 4. Double coordinate system. (a) Intersections between carrier and modulation waves of phase opposition disposition SPWM. (b) Intersections between carrier and modulation wave of carrier phase shifted SPWM. (c) Details of carrier and modulation wave of case (2). (d) Details of carrier and modulation wave of case (4).

Intersections between modulation wave and carrier are figured out in $\theta$-axis. Within a period of a triangular wave, there are two line segments $y_{1}(\theta)$ and $y_{2}(\theta)$ shown in Figure $4 \mathrm{c}$. Slope of $y_{1}(\theta)$ is $-2 \theta / \pi$, and slope of $y_{2}(\theta)$ is $+2 \theta / \pi$. There are two equations: $y_{1}(\theta)=A_{2} \cos \varphi+1, y_{2}(\theta)=A_{2} \cos \varphi+1$. Then the abscissa values of two intersection points can be obtained, shown in Figure 4c. Finally, output level is obtained by comparing the amplitudes of carrier and modulation wave.

When this double coordinate system is used to analyze the equivalent carrier phase shifted SPWM strategy, only one layer of carrier exists, and the switching function of each bridge in a cascaded inverter can be deduced in one double coordinate system.

In this case, $\theta$-axis and $\varphi$-axis will be completely overlapped. Similarly, $\varphi$ is defined as the abscissa values of the intersections between the modulating signal and carrier envelope line, and $\theta$ is defined as abscissa values of intersections between modulation wave and carrier. However, intersections between modulation wave and carrier should be analyzed within a period of carrier and a period of modulation wave, respectively, as shown in Figure 4b,d.

There are two different cases of intersections between carriers and modulation wave, as shown in Figure $4 \mathrm{~b}$. Obviously, if the magnitude of modulation wave is higher than peak value of carriers (modulation depth $M>1$ ), modulation wave and envelopes intersects the envelope line. When $M<1$, modulation wave is inside the area surrounded by the two envelopes. Within a period of a triangle carrier, the intersections of modulation wave and two carriers are expressed as $\theta_{\mathrm{a}}, \theta_{\mathrm{b}}$ and $\theta_{\mathrm{a}}{ }^{\prime}, \theta_{\mathrm{b}}{ }^{\prime}$, as shown in Figure 4d. Apparently, the method to determine the spectral characteristics of equivalent SPWM can be used to simplify spectrum analysis of phase opposition disposition SPWM.

\subsection{Modulation of NPC Cascaded Inverter}

Phase opposition disposition SPWM for one single-phase NPC module can be realized as shown in Figure 3c, in which $C_{a 1}, C_{a 2}$ are triangular carriers of bridge Leg a and $C_{b 1}, C_{b 2}$ represent that of bridge Leg $b$. Modulation strategy for Leg a and Leg $b$ in one module is similar. It should be emphasized that phase difference between modulation waves of two bridge legs is $180^{\circ}$. And that between carriers of two bridge legs is also $180^{\circ}$. Then five-level waveform is obtained, as shown in Figure 3c.

As shown in Figure 5, carrier phase shifted SPWM is adopted for single-phase NPC cascaded inverter because of its performance for cascaded system. Modulation strategy for each single module is almost the same. It is noted that: When $N$ (number of NPC modules) is odd, the triangular carriers sequentially move forward $2 \pi / N$. When $N$ is even, the triangular carriers sequentially move backward $\pi / N$. Otherwise, output level will decrease and harmonic content will increase. Carrier phase shifted SPWM can split the duty time of the vector to equalize the voltages of separate cascaded modules with higher switching frequency. 




Figure 5. Carrier Phase Shifted SPWM for NPC Cascaded Inverter.

\section{Output Spectrum of Single-Phase NPC Cascaded Inverter}

\subsection{Derivation of Switching Function}

The output waveform is the function of $\theta$ and $\varphi$. When modulation depth of one NPC module $M$ $>1, \varphi_{0}$ is defined as the intersection between modulation wave and upper carrier envelope line, and $\varphi_{0}{ }^{\prime}$ is defined as intersection between modulation wave and lower carrier envelope line. Moreover, $\varphi_{0}$ $+\varphi_{0}{ }^{\prime}=\pi$. When $M \leq 1$, there is no intersection between modulation wave and two carrier envelope lines, which means $\varphi_{0}=0$, as shown in Figure $4 \mathrm{c}$,d.

In this paper, the switching function spectrum is deduced when $M<1$, and it means the single-phase NPC cascaded inverter works in linear conditions. Within a period of a triangle carrier, the intersections of modulation wave and two carriers, $\theta_{1}, \theta_{2}$ and $\theta_{1}{ }^{\prime}, \theta_{2}{ }^{\prime}$ in Figure $3 \mathrm{~b}$ can be expressed as follows:

$$
\begin{gathered}
\left\{\begin{array}{c}
\theta_{1}=-\frac{\pi\left(A_{v} \cos \varphi+1\right)}{2} \\
\theta_{2}=\frac{\pi\left(A_{v} \cos \varphi+1\right)}{2}
\end{array}\right. \\
\left\{\begin{array}{c}
\theta_{1}{ }^{\prime}=\frac{\pi\left(A_{v} \cos \varphi-1\right)}{2} \\
\theta_{2}{ }^{\prime}=-\frac{\pi\left(A_{v} \cos \varphi-1\right)}{2}
\end{array}\right.
\end{gathered}
$$

According to Section 3, in a double coordinate system, the values of switching function within a period of carrier and modulation wave are obtained as follows:

$$
F(\theta, \varphi)=\left\{\begin{array}{l}
0, \quad-\pi \leq \varphi \leq-\left(\pi-\varphi_{0}\right), \quad-\pi \leq \theta \leq \pi \\
0, \quad-\left(\pi-\varphi_{0}\right) \varphi \leq-\varphi_{0},-\pi \leq \theta \leq \theta_{1} \\
1, \quad-\left(\pi-\varphi_{0} \leq \varphi \leq-\varphi_{0}, \quad \theta_{1} \theta \theta_{2}\right. \\
0, \quad-\left(\pi-\varphi_{0} \leq \varphi \leq-\varphi_{0}, \quad \theta_{2} \theta \pi\right. \\
1, \quad-\varphi_{0} \leq \varphi \varphi_{0}, \quad-\pi \theta \pi \\
0, \quad \varphi_{0} \leq \varphi \leq \pi-\varphi_{0}, \quad-\pi \leq \theta<\theta_{1} \\
1, \quad \varphi_{0} \leq \varphi \leq \pi-\varphi_{0}, \quad \theta_{1} \leq \theta \leq \theta_{2} \\
0, \quad \varphi_{0} \leq \varphi \leq \pi-\varphi_{0}, \quad \theta_{2} \theta \leq \pi \\
0, \quad \pi-\varphi_{0} \leq \varphi \leq \pi, \quad-\pi \theta \pi
\end{array}\right.
$$

\subsection{Derivation of Output Spectrum of CPSPOD-SPWM}

As shown in Figure 6a, the effective domain of integration is drawn according to the value distribution of 0 and 1 of $F(\theta, \varphi)$, and the gray segment represents the area in which value is 1 . If the initial angle of carrier $\alpha$ shifts $180^{\circ}$, the effective domain of integration shown in Figure $6 \mathrm{~b}$ can be obtained. 


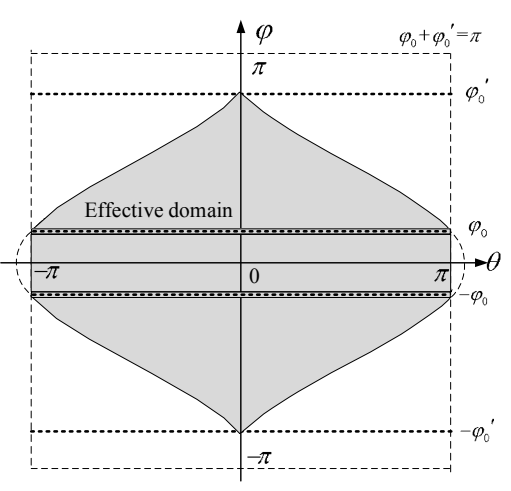

(a)

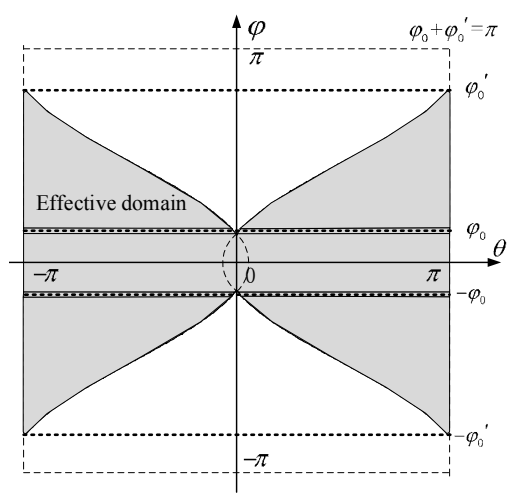

(b)

Figure 6. Effective domain of integration. (a) Effective domain (Initial angle of carrier $\alpha=0$ ). (b) Effective domain (Initial angle of carrier $\alpha=\pi$ ).

$F(\theta, \varphi)$ is a periodic function in terms of $\theta$ and $\varphi$. Therefore, it can be expressed by double Fourier series as follows:

$$
\begin{aligned}
F(\theta, \varphi)= & \frac{1}{2} A_{00}+\sum_{n=1}^{\infty}\left[A_{0 n} \cos n \varphi+B_{0 n} \sin n \varphi\right] \\
& +\sum_{m=1}^{\infty} \sum_{n=0}^{ \pm \infty}\left[A_{m n} \cos (m \theta+n \varphi)+B_{m n} \sin (m \theta+n \varphi)\right]
\end{aligned}
$$

Because the carrier wave and sinusoidal modulation wave are symmetric about $\theta=0$ and $\varphi=0$, the value of $B_{m n}$ is 0 . Then $A_{\mathrm{mn}}(m=0,1,2 \ldots)$ can be obtained by inverse transformation of double Fourier function. In linear modulation region, two PWM waves of bridge Leg a are expressed by double Fourier series as follows:

$$
\begin{gathered}
F_{P W M 1}\left(\omega_{c} t, \omega_{v} t\right)=\frac{M}{4} \cos \left(\omega_{\mathrm{s}} t\right)+\frac{1}{m \pi} \sum_{m=1,3,5, \cdots}^{\infty}\left[J_{0}\left(\frac{m M \pi}{2}\right) .\right. \\
\left.\sin \left(\frac{m}{2} \pi\right) \cos \left(m \omega_{c} t\right) \mathrm{e}^{-\mathrm{jm} \alpha}\right]+\frac{1}{m \pi} \sum_{m=1,2, \cdots}^{\infty} \sum_{n= \pm 1, \pm 2, \cdots}^{ \pm \infty}\left[J_{n}\left(\frac{m M \pi}{2}\right) .\right. \\
\left.\sin \left(\frac{m+n}{2} \pi\right) \mathrm{e}^{-\mathrm{jm} \alpha} \cos \left(m F \omega_{v} t+n \omega_{v} t+n \frac{\pi}{2}\right)\right] \\
F_{P W M 2}\left(\omega_{c} t, \omega_{v} t\right)=\frac{M}{4} \cos \left(\omega_{v} t\right)+\frac{1}{m \pi} \sum_{m=1,3,5, \cdots}^{\infty}\left[J_{0}\left(\frac{m M \pi}{2}\right) .\right. \\
\left.\sin \left(\frac{m}{2} \pi\right) \cos \left(m \omega_{c} t\right) \mathrm{e}^{-j \mathrm{~m}(\alpha+\pi)}\right]+\frac{1}{m \pi} \sum_{m=1,2, \cdots n= \pm 1, \pm 2, \cdots}^{\infty} \sum_{n}^{ \pm \infty}\left[J_{n}\left(\frac{m M \pi}{2}\right)\right. \\
\left.\cdot \sin \left(\frac{m+n}{2} \pi\right) \mathrm{e}^{-j \mathrm{j}(\alpha+\pi)} \cos \left(m F \omega_{v} t+n \omega_{v} t+n \frac{\pi}{2}\right)\right]
\end{gathered}
$$

where $A v$ is the amplitude of the modulation wave; $A c$ is the peak value of the triangular carrier; $M$ is the modulation depth, given by the expression $M=A v / A c ; \omega_{v}$ is the angular velocity of the modulation wave; $\omega_{c}$ is the angular velocity of triangular carrier; $F$ is the carrier wave ratio $\left(F=\omega_{v} / \omega_{c}\right)$; and $J_{n} \frac{m M \pi}{2}$ represents the Bessel function as follows:

$$
J_{n}\left(\frac{m M \pi}{2}\right)=\frac{1}{2 \pi} \int_{-\pi}^{\pi} \mathrm{e}^{-j \frac{m M \pi}{2}} \cdot \mathrm{e}^{j n \tau} \cdot d \tau
$$


Adding (5) and (6), the output spectrum of one bridge leg is deduced as follows:

$$
\begin{aligned}
& F_{a}\left(\omega_{c} t, \omega_{v} t\right)=F_{P W M 1}\left(\omega_{c} t, \omega_{v} t\right)+F_{P M W 2}\left(\omega_{c} t, \omega_{v} t\right)= \\
& \frac{M}{2} \cos \left(\omega_{v} t\right)+\mathrm{e}^{-\mathrm{jm} \alpha}\left(1+\mathrm{e}^{-\mathrm{jm} \pi}\right) \frac{1}{m \pi} \sum_{m=1,3,5 \cdots}^{\infty}\left[J_{0}\left(\frac{m M \pi}{2}\right) \sin \left(\frac{m}{2} \pi\right)\right. \\
& \left.\cdot \cos \left(m \omega_{c} t\right)\right]+\mathrm{e}^{-\mathrm{jm} \alpha}\left(1+\mathrm{e}^{-\mathrm{jm} \pi}\right) \frac{1}{m \pi} \sum_{m=1,2, \cdots}^{\infty} \sum_{n= \pm 1, \pm 2, \cdots}^{ \pm \infty}\left[J_{n}\left(\frac{m M \pi}{2}\right)\right. \\
& \left.\cdot \sin \left(\frac{m+n}{2} \pi\right) \cos \left(m F \omega_{v} t+n \omega_{v} t+n \frac{\pi}{2}\right)\right]
\end{aligned}
$$

When $m$ is an odd number, $1+\mathrm{e}^{-\mathrm{jm} \pi}=0$, hence the second term is eliminated. When POD-SPWM strategy is adopted, frequency of triangular carriers is doubled, and carrier wave ratio is also doubled, then $F^{\prime}=2 F, m^{\prime}=m / 2$. The Equation (8) can be simplified as follows:

$$
\begin{aligned}
F_{a}\left(\omega_{c} t, \omega_{v} t\right)= & \left.\left.\frac{M}{2} \cos \left(\omega_{v} t\right) \pm \frac{1}{m^{\prime} \pi} \mathrm{e}^{-\mathrm{jm} / \alpha} \sum_{m^{\prime}=1,2, \cdots n= \pm 1, \pm 3, \cdots}^{\infty} \sum_{n=1}^{ \pm \infty} \frac{m^{\prime}}{2}\right) \cdot \sin \left(m^{\prime} F^{\prime} \omega_{v} t+n \omega_{v} t+n \frac{\pi}{2}\right)\right] \\
& {\left[J_{n}\left(\frac{m^{\prime} M \pi}{2}\right)\right.}
\end{aligned}
$$

For Leg $b$, the initial triangular carrier has a $180^{\circ}$ phase difference compared with the carrier of Leg a, and modulation wave can be described as $-A_{\nu} \cos \left(\omega_{v} t\right)$. The derivation of output voltage spectrum is similar as the Equations (1)-(9).The expression is shown as follows:

$$
\begin{aligned}
F_{b}\left(\omega_{c} t, \omega_{v} t\right)= & -\frac{M}{2} \cos \left(\omega_{v} t\right) \mp \frac{1}{m^{\prime} \pi} \mathrm{e}^{-\mathrm{jm} / \alpha} \sum_{m^{\prime}=1,2, \cdots n= \pm 1, \pm 3, \cdots}^{\infty} \sum_{n}^{ \pm \infty} \\
& {\left[J_{n}\left(\frac{m^{\prime} M \pi}{2}\right) \cdot \sin \left(m^{\prime} F^{\prime} \omega_{v} t+n \omega_{v} t+n \frac{\pi}{2}\right)\right] }
\end{aligned}
$$

Then, the output voltage spectrum of single-phase NPC is expressed as follows:

$$
\begin{aligned}
F_{N P C}\left(\omega_{c} t, \omega_{v} t\right)= & F_{a}\left(\omega_{c} t, \omega_{v} t\right)-F_{b}\left(\omega_{c} t, \omega_{v} t\right) \\
= & M \cos \left(\omega_{v} t\right)+\mathrm{e}^{-\mathrm{jm} / \alpha} \frac{2}{m^{\prime} \pi} \sum_{m^{\prime}=2,4, \cdots n= \pm 1, \pm 3, \cdots}^{\infty} \sum^{ \pm \infty} \\
& {\left[J_{n}\left(\frac{m^{\prime} M \pi}{2}\right) \cdot \sin \left(m^{\prime} F^{\prime} \omega_{v} t+n \omega_{v} t+n \frac{\pi}{2}\right)\right] }
\end{aligned}
$$

When an odd number of NPC modules are cascaded, suppose the initial phase angle of triangular carrier of the first NPC module $\alpha_{1 \_1}=0^{\circ}$, then that angle of module $i \alpha_{\mathrm{i}_{-} 1}=2 \pi(i-1) / N$. If regard $F_{N P C i}$ as a function of $\omega_{c} t, \omega_{v} t, \alpha_{i \_1}$, combining the derivation of Equation (11), the output spectrum of module $i$ is obtained:

$$
\begin{aligned}
& F_{N P C i}\left(\omega_{c} t, \omega_{v} t, \alpha_{i} 1\right)=M \cos \left(\omega_{v} t\right)+\mathrm{e}^{-\mathrm{jm} / \alpha_{i_{-} 1}} \frac{2}{m^{\prime} \pi} . \\
& \sum_{m^{\prime}=2,4, \cdots n= \pm 1, \pm 3, \cdots}^{\infty} \sum_{n}^{ \pm \infty}\left[J_{n}\left(\frac{m^{\prime} M \pi}{2}\right) \cdot \sin \left(m^{\prime} F^{\prime} \omega_{v} t+n \omega_{v} t+n \frac{\pi}{2}\right)\right]
\end{aligned}
$$

Adding $N$ output spectral expressions of single-phase NPC modules, the total output voltage spectrum of cascaded structure is expressed as follows:

$$
\begin{aligned}
& F_{N P C \_O d d}=\sum_{i=1}^{N} F_{N P C i}\left(\omega_{c} t, \omega_{v} t, \alpha_{i \_1}\right) \\
& =N M \cos \left(\omega_{v} t\right)+\left(e^{-\mathrm{jm} / \alpha_{i} 1}+e^{-\mathrm{j} m / \alpha_{i} 2}+\ldots+e^{-\mathrm{j} m / \alpha_{i} N}\right) \frac{2}{m^{\prime} \pi} . \\
& \left.\sum_{m^{\prime}=2,4, \cdots n= \pm 1, \pm 3, \cdots}^{\infty} \sum_{n}^{ \pm \infty}\left[\frac{m^{\prime} M \pi}{2}\right) \cdot \sin \left(m^{\prime} F^{\prime} \omega_{v} t+n \omega_{v} t+n \frac{\pi}{2}\right)\right]
\end{aligned}
$$


Defining $G=e^{-\mathrm{jm} / \alpha_{i_{-} 1}}+e^{-\mathrm{jm} / \alpha_{i-2}}+\ldots+e^{-\mathrm{jm} / \alpha_{i-N}}$, the value of $G$ is $N$ when $m^{\prime}=k \cdot N(\mathrm{k}$ is an arbitrary integer), in other cases, the value is 0 . Therefore, the expression of total output voltage can be simplified as follows:

$$
\begin{aligned}
F_{N P C_{-} O d d=}= & N M \cos \left(\omega_{v} t\right)+\frac{2 N}{m^{\prime} \pi} \cdot \sum_{m^{\prime}=2 N, 4 N, \cdots n= \pm 1, \pm 3, \cdots}^{\infty} \sum^{ \pm \infty} \\
& {\left[J_{n}\left(\frac{m^{\prime} M \pi}{2}\right) \sin \left(m^{\prime} F^{\prime} \omega_{v} t+n \omega_{v} t+n \frac{\pi}{2}\right)\right] }
\end{aligned}
$$

For the total output voltage $F_{\text {NPC-Even }}$ (NPC-Even/Odd indicates even/Odd number of NPCs are cascaded), because of the difference $\pi / N$ among initial phase angles of NPC modules, the value of $G$ is $N$ when $m=2 k \cdot N$ ( $\mathrm{k}$ is an arbitrary integer). In other cases, the value is not always 0 . Thus, the expression is same as Equation (14).

\section{Simulation and Experiment}

In order to verify the theoretical analysis, a simulation is performed in the Matlab/Simulink environment. By simulations of a single NPC, two NPC modules and three NPC modules cascaded structures, 5-level, 9-level and 13-level output waveforms are obtained, then the output waveforms are analyzed by fast Fourier transform (FFT). The simulation parameters are listed in Table 2 and the results are shown in Figure 7. The simulation parameters are shown in Table 2.

Table 2. Simulation Parameters.

\begin{tabular}{cc}
\hline Parameters & Value \\
\hline DC capacitor $C_{1}, C_{2} C_{3}, C_{4}$ & $20 \mathrm{mF}$ \\
DC bus voltage & $3000 \mathrm{~V}$ \\
Frequency of modulated wave & $50 \mathrm{~Hz}$ \\
Modulation depth & 0.98 \\
Frequency of carrier $\left(f_{\mathrm{c}}\right)$ & $3000 \mathrm{~Hz}$ \\
Simulation step & $1 \times 10^{-6} \mathrm{~s}$ \\
Simulation time & $0.05 \mathrm{~s}$ \\
\hline
\end{tabular}

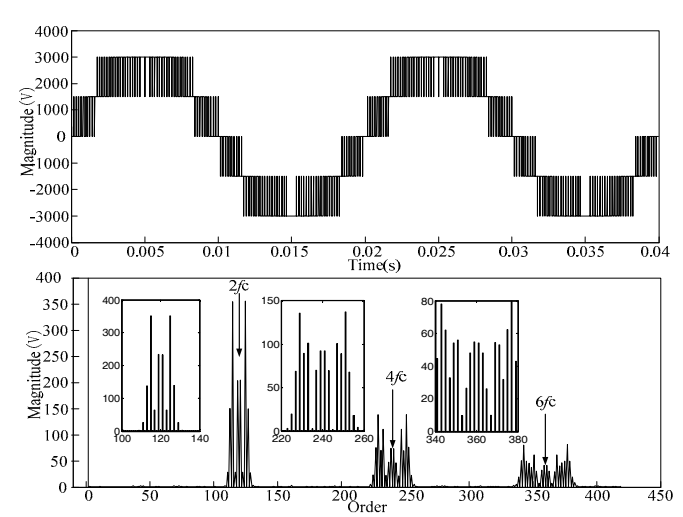

(a)

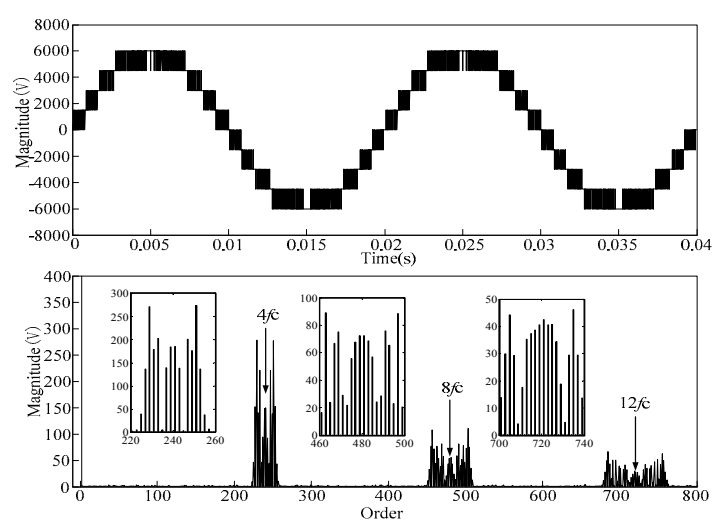

(b)

Figure 7. Cont. 


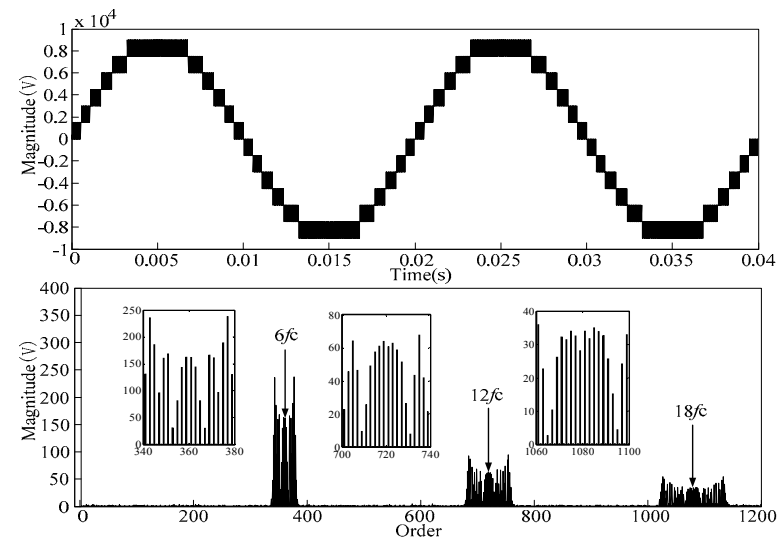

(c)

Figure 7. Simulation Results. (a) 1 module. (b) 2 modules cascaded inverter. (c) 3 modules cascaded inverter.

\subsection{Simulation}

When three modules are cascaded, the total harmonic distortion (THD) of a five-level output waveform is $26.98 \%$, and the fundamental amplitude is $2940 \mathrm{~V}$. When five modules are cascaded, THD of nine-level output waveform is $13.27 \%$, and the fundamental amplitude is $5881 \mathrm{~V}$. When seven modules are cascaded, THD of thirteen-level is $9.89 \%$, the fundamental amplitude is $8821 \mathrm{~V}$. For nine-level output waveform (thirteen-level output waveform), the contents of the odd harmonics in $4 f_{c}, 8 f_{c}, 12 f_{c}\left(6 f_{c}, 12 f_{c}, 18 f_{c}\right)$ side-frequency bands are shown in Table 3.

The simulation results indicate that odd harmonics mainly exist in side-frequency band of which the frequency is $2 N(4 N, \ldots)$ times carrier frequency Compared with single module, the equivalent switching frequency of the NPC-CI is N times higher, while the THD is much smaller. The output spectrum barely contains the harmonic of the carrier frequency or the low orders harmonics.

In actual engineering application, the maximum voltage present commercialized IGBTs can withstand is $6.5 \mathrm{kV}$. Thus, considering redundant design in cascaded system, the number of cascaded modules is set to $7+1$. The output waveform and spectrum of an eight modules cascaded single-phase NPC-CI are shown in Figure 8.

When the modulation depth is 0.98 , a 33-level output waveform is achieved, and the theoretical maximum output voltage root mean square (RMS) is obtained in this case. When the modulation depth is reduced to 0.69 , the output voltage RMS is nearly $27.5 \mathrm{kV}$, which is the standard voltage of a traction net. In this case, even though the voltage level number is reduced and THD is increased, the output voltage waveform is still sinusoidal. By analyzing the output spectrum, it is found that decrease of voltage levels has little impact on the harmonic distribution, and harmonics mainly exist in side-frequency band of which frequency is $N \times 8 \times 2 f_{\mathrm{c}}(N=1,2,3, \ldots)$. Thus, switching frequency and switching loss are decreased with increasing output voltage-levels. Meanwhile, filter circuit of cophase power supply system can be cancelled. 
Table 3. Output Characteristic Order Harmonics Content of 2 Modules Cascaded Inverter and 3 Modules Cascaded Inverter.

\begin{tabular}{|c|c|c|c|c|c|c|c|c|c|c|c|c|c|c|c|c|}
\hline \multirow{6}{*}{ 9-level } & Order & 227 & 229 & 231 & 233 & 235 & 237 & 239 & 240 & 241 & 243 & 245 & 247 & 249 & 251 & 253 \\
\hline & Content (\%) & 2.53 & 4.63 & 2.34 & 3.68 & 0.06 & 2.36 & 3.15 & 0 & 3.12 & 2.37 & 0.08 & 3.68 & 2.31 & 4.62 & 2.54 \\
\hline & Order & 467 & 469 & 471 & 473 & 475 & 477 & 479 & 480 & 481 & 483 & 485 & 487 & 489 & 491 & 493 \\
\hline & Content (\%) & 0.64 & 1.35 & 0.49 & 0.41 & 0.97 & 1.16 & 1.23 & 0 & 1.23 & 1.15 & 0.95 & 0.37 & 0.49 & 1.27 & 0.68 \\
\hline & Order & 707 & 709 & 711 & 713 & 715 & 717 & 719 & 720 & 721 & 723 & 725 & 727 & 729 & 731 & 733 \\
\hline & Content $(\%)$ & 0.68 & 0.54 & 0.20 & 0.15 & 0.30 & 0.40 & 0.50 & 0 & 0.47 & 0.45 & 0.34 & 0.10 & 0.23 & 0.54 & 0.70 \\
\hline \multirow{6}{*}{ 13-level } & Order & 347 & 349 & 351 & 353 & 355 & 357 & 359 & 360 & 361 & 363 & 365 & 367 & 369 & 371 & 373 \\
\hline & Content (\%) & 1.09 & 1.81 & 1.91 & 0.35 & 0.92 & 1.63 & 1.84 & 0 & 1.84 & 1.63 & 0.92 & 0.34 & 1.88 & 1.83 & 1.1 \\
\hline & Order & 707 & 709 & 711 & 713 & 715 & 717 & 719 & 720 & 721 & 723 & 725 & 727 & 729 & 731 & 733 \\
\hline & Content (\%) & 0.52 & 0.11 & 0.29 & 0.55 & 0.65 & 0.69 & 0.72 & 0 & 0.72 & 0.69 & 0.67 & 0.58 & 0.3 & 0.09 & 0.49 \\
\hline & Order & 1067 & 1069 & 1071 & 1073 & 1075 & 1077 & 1079 & 1080 & 1081 & 1083 & 1085 & 1087 & 1089 & 1091 & 1093 \\
\hline & Content $(\%)$ & 0.12 & 0.3 & 0.37 & 0.36 & 0.39 & 0.37 & 0.32 & 0 & 0.39 & 0.36 & 0.4 & 0.38 & 0.37 & 0.29 & 0.17 \\
\hline
\end{tabular}

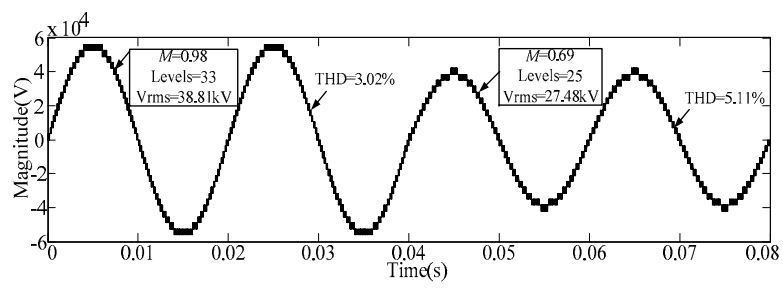

(a)

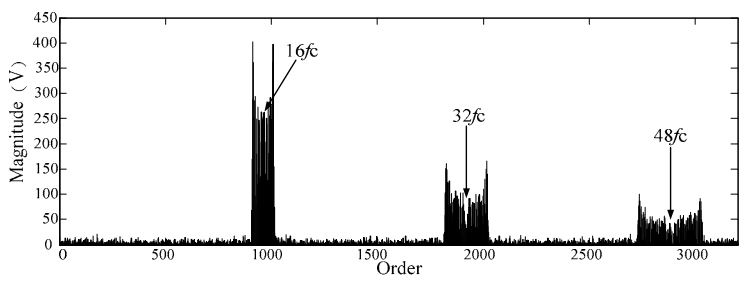

(b)



(c)

Figure 8. Simulation Results of an eight modules cascaded inverter with carrier phase shifted phase opposition disposition SPWM. (a) Output waveform. (b) Output spectrum $(M=0.98)$. (c) Output spectrum $(M=0.69)$. 
The simulation results of an eight modules cascaded inverter with carrier phase shifted phase opposition disposition SPWM is shown in Figure 8. According to Equations (10) and (13), with different values of $\mathrm{m}$ and $\mathrm{n}$, the ratio of $i$-th harmonic amplitude to fundamental amplitude can be calculated, which is represented as HRUi. When output waveforms are of 5-level, 9-level and 13-level, HRUi of first, third and fifth harmonics in side-frequency band of characteristic harmonic are counted in Table 4 . By comparison, simulation results are consistent with theoretical results.

Table 4. Comparison between Simulation Results and Theoretical Results.

\begin{tabular}{cccccccc}
\hline \multirow{2}{*}{ Output Level } & \multicolumn{3}{c}{ Simulation Results } & \multicolumn{3}{c}{ Theoretical Results } \\
\cline { 2 - 8 } & HRU $_{\mathbf{i}}$ & $\boldsymbol{n = 1}$ & $\boldsymbol{n = 3}$ & $\boldsymbol{n = 5}$ & $\boldsymbol{n = 1}$ & $\boldsymbol{n = 3}$ & $\boldsymbol{n}=\mathbf{5}$ \\
\hline \multirow{2}{*}{ 5-level } & $m=2$ & 7.92 & 2.17 & 11.96 & 7.89 & 2.18 & 12.10 \\
& $m=4$ & 3.14 & 2.39 & 0.09 & 3.12 & 2.36 & 0.08 \\
\hline \multirow{2}{*}{ 9-level } & $m=4$ & 3.12 & 2.37 & 0.08 & 3.12 & 2.36 & 0.08 \\
& $m=8$ & 1.23 & 1.15 & 0.95 & 1.25 & 1.17 & 0.93 \\
\hline \multirow{2}{*}{ 13-level } & $m=6$ & 1.84 & 1.63 & 0.92 & 1.83 & 1.61 & 0.96 \\
& $m=12$ & 0.72 & 0.69 & 0.65 & 0.71 & 0.70 & 0.66 \\
\hline
\end{tabular}

\subsection{Low Power Experiment}

Low power experimental platform is shown in Figure 9a. Basically, it consists of a control board, fiber board and IGBT driver board and DC source, etc. The carrier frequency is $1.4 \mathrm{kHz}$ and modulation wave frequency is $50 \mathrm{~Hz}$. Modulation depth is set to be 0.85 .

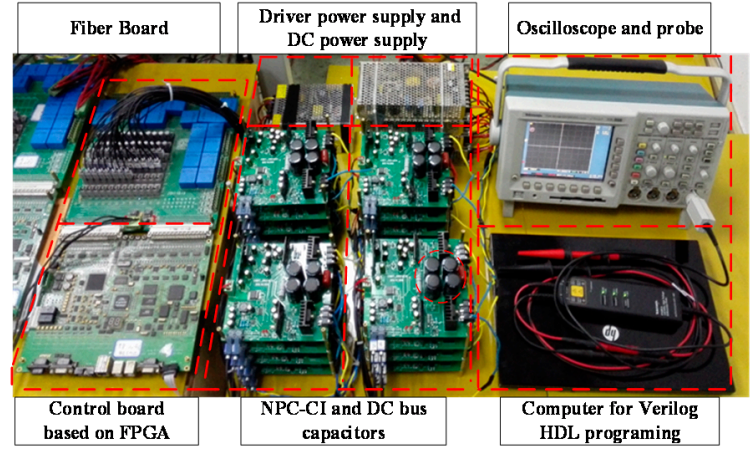

(a)

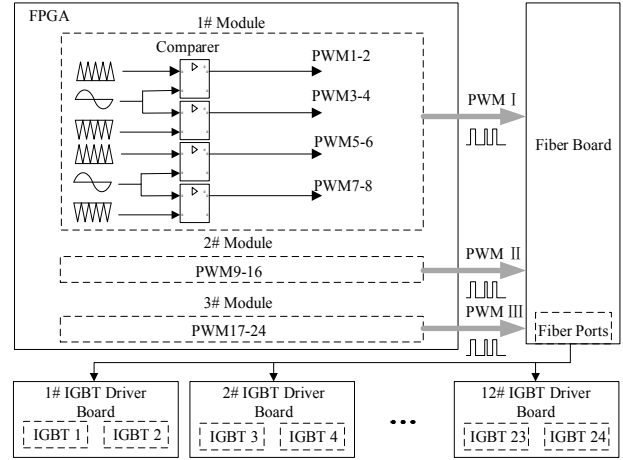

(b)

Figure 9. Experimental platform. (a) Prototype of Single-phase NPC-CI. (b) Control Strategy.

Taking a three-modules prototype for example, the control strategy is shown in Figure 9b. At present, because the number of fiber ports is limited, experimental platforms of one single module, cascaded structures consisted of two modules and three modules are set up to verify the deduction. Expressions of output voltage of single module and cascaded structure are expanded by FFT, as shown in Figure 10. Output characteristic order harmonics content of a two modules cascaded structure and a three modules cascaded structure are counted in Table 3. Experimental results are consistent with our theoretical analysis. 


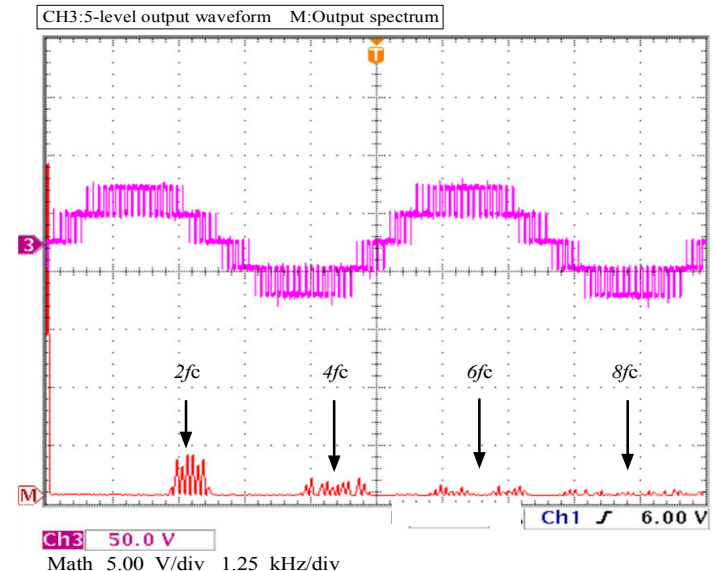

(a)



Math $5.00 \mathrm{~V} / \mathrm{div} 2.5 \mathrm{kHz} / \mathrm{div}$

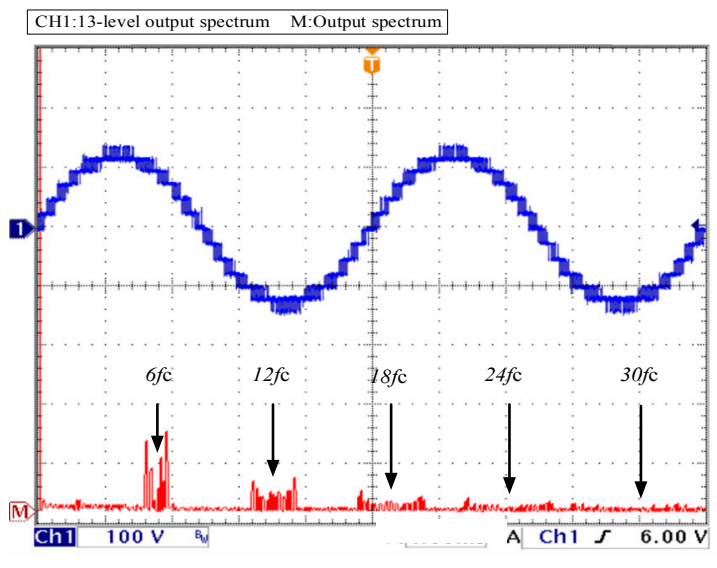

(c)

Figure 10. Experimental results. (a) Voltage and spectrum of a one modules inverte. (b) Voltage and spectrum of a two modules cascaded inverter. (c) Voltage and spectrum of a three modules cascaded inverter.

\section{Conclusions}

An advanced traction power supply system based on a single phase NPC cascaded inverter is studied in this paper. The big triangular carrier equivalence method in double coordinate system is proposed, to simplify the complexity of the calculations. On the basis of the proposed method, the harmonic characteristics of single phase NPC cascaded inverter are calculated by a double Fourier series. The performances and calculation results of the proposed method were verified by simulations and experiments. The conclusions are as follows:

(1) The equivalent switching frequency of the output voltage increases by adding a certain number of cascaded single-phase NPC module-based cascaded structures, and the frequency of the odd harmonics which exist in the side frequency band of mainly is $2 N(4 N, \ldots)$ times higher than the carrier frequency, where $N$ represents the number of NPC modules;

(2) The output spectrum barely contains the harmonics of the carrier frequency or lower order harmonics. Meanwhile, the output voltage becomes better regulated and the THD becomes much lower with the increasing number of cascaded modules.

(3) The method proposed in the paper to analyze the harmonic characteristic is proved to be correct by simulations and experiments. The harmonic characteristics of an advanced traction power 
supply system based on a single phase NPC cascaded inverter analyzed in this paper provides a theoretical way to avoid railway traction network resonance.

Acknowledgments: This work was supported by the National Natural Science Foundation of China (Grant Nos. 51477144).

Author Contributions: Pengcheng Han and Xiaoqiong He conceived the strategy and the experiment; Yi Wang performed the experiment; Haijun Ren wrote the paper; Xu Peng analyzed the data; and Zeliang Shu contributed experiment prototype.

Conflicts of Interest: The authors declare no conflict of interest.

\section{References}

1. Nabae, A.; Takahashi, I.; Akagi, H. A New Neutral-Point-Clamped PWM Inverter. IEEE Trans. Ind. Appl. 1981, IA-17, 518-523. [CrossRef]

2. Rodriguez, J.; Bernet, S.; Steimer, P.K.; Lizama, I.E. A Survey on Neutral-Point-Clamped Inverters. IEEE Trans. Ind. Electron. 2010, 57, 2219-2230. [CrossRef]

3. Ge, B.; Peng, F.Z.; de Almeida, A.T.; Abu-Rub, H. An Effective Control Technique for Medium-Voltage High-Power Induction Motor Fed by Cascaded Neutral-Point-Clamped Inverter. IEEE Trans. Ind. Electron. 2010, 57, 2659-2668.

4. Spichartz, M.; Staudt, V.; Steimel, A. Modular Multilevel Converter for propulsion system of electric ships. In Proceedings of the 2013 IEEE Electric Ship Technologies Symposium ESTS, Arlington, VA, USA, 22-24 April 2013; pp. 237-242.

5. He, X.; Guo, A.; Peng, X.; Zhou, Y.; Shi, Z.; Shu, Z. A Traction Three-Phase to Single-Phase Cascade Converter Substation in an Advanced Traction Power Supply System. Energies 2015, 8, 9915-9929. [CrossRef]

6. Hu, H.; He, Z.; Gao, S. Passive Filter Design for China High-Speed Railway With Considering Harmonic Resonance and Characteristic Harmonics. IEEE Trans. Power Deliv. 2015, 30, 505-514. [CrossRef]

7. He, Z.; Hu, H.; Zhang, Y.; Gao, S. Harmonic Resonance Assessment to Traction Power-Supply System Considering Train Model in China High-Speed Railway. IEEE Trans. Power Deliv. 2014, 29, 1735-1743. [CrossRef]

8. Lao, K.W.; Dai, N.; Liu, W.G.; Wong, M.C. Hybrid Power Quality Compensator with Minimum DC Operation Voltage Design for High-Speed Traction Power Systems. IEEE Trans. Power Electron. 2013, 28, 2024-2036. [CrossRef]

9. Shu, Z.; Xie, S.; Li, Q. Single-Phase Back-To-Back Converter for Active Power Balancing, Reactive Power Compensation, and Harmonic Filtering in Traction Power System. IEEE Trans. Power Electron. 2011, 26, 334-343. [CrossRef]

10. He, X.; Shu, Z.; Peng, X.; Zhou, Q.; Zhou, Y.; Zhou, Q.; Gao, S. Advanced Cophase Traction Power Supply System Based on Three-Phase to Single-Phase Converter. IEEE Trans. Power Electron. 2014, 29, 5323-5333. [CrossRef]

11. Tooth, D.J.; Finney, S.J.; Williams, B. Fourier theory of jumps applied to converter harmonic analysis. IEEE Trans. Aerosp. Electron. Syst. 2001, 37, 109-122. [CrossRef]

12. Kwon, J.; Wang, X.; Blaabjerg, F.; Bak, C.L.; Sularea, V.S.; Busca, C. Harmonic Interaction Analysis in a Grid-Connected Converter Using Harmonic State-Space (HSS) Modeling. IEEE Trans. Power Electron. 2017, 32, 6823-6835. [CrossRef]

13. Bai, H.; Wang, X.; Blaabjerg, F.; Loh, P.C. Harmonic Analysis and Mitigation of Low-Frequency Switching Voltage Source Inverter with Auxiliary VSI. IEEE J. Emerg. Sel. Top. Power Electron. 2017. [CrossRef]

14. Madhusoodhanan, S.; Mainali, K.; Tripathi, A.; Patel, D.; Kadavelugu, A.; Bhattacharya, S.; Hatua, K. Harmonic Analysis and Controller Design of $15 \mathrm{kV}$ SiC IGBT-Based Medium-Voltage Grid-Connected Three-Phase Three-Level NPC Converter. IEEE Trans. Power Electron. 2017, 32, 3355-3369. [CrossRef]

15. Rezaei, S. An adaptive algorithm based on sub harmonic and time domain analysis to prevent mal operation of overcurrent relay during Sub Synchronous Resonance. IEEE Trans. Ind. Appl. 2018. [CrossRef]

16. Lv, G.; Zeng, D.; Zhou, T. Analysis of Secondary Losses and Efficiency in Linear Induction Motors with Composite Secondary Based on Space Harmonic Method. IEEE Trans. Energy Convers. 2017, 32, 1583-1591. [CrossRef] 
17. Vahedi, H.; Labbe, P.; Al-Haddad, K. Balancing three-level neutral point clamped inverter DC bus using closed-loop space vector modulation: Real-time implementation and investigation. IET Power Electron. 2016, 9, 2076-2084. [CrossRef]

18. He, X.; Lin, X.; Peng, X.; Han, P.; Shu, Z.; Gao, S. Control strategy of single-phase Three Level Neutral Point Clamped Cascaded Rectifier. Energies 2017, 10, 1-16.

19. McGrath, B.P.; Holmes, D.G. Multicarrier PWM strategies for multilevel inverters. IEEE Trans. Ind. Electron. 2002, 49, 858-867. [CrossRef]

20. Agelidis, V.G.; Calais, M. Application specific harmonic performance evaluation of multicarrier PWM techniques. In Proceedings of the 1998 PESC Records Annual IEEE Power Electronics Specialists Conference, Fukuoka, Japan, 22 May 1998; pp. 172-178.

21. Holmes, D.G.; McGrath, B.P. Opportunities for harmonic cancellation with carrier-based PWM for a two-level and multilevel cascaded inverters. IEEE Trans. Ind. Appl. 2001, 37, 574-582. [CrossRef]

22. Sebaaly, F.; Vahedi, H.; Kanaan, H.Y.; Moubayed, N.; Al-Haddad, K. Design and Implementation of Space Vector Modulation-Based Sliding Mode Control for Grid-Connected 3L-NPC Inverter. IEEE Trans. Ind. Electron. 2016, 63, 7854-7863. [CrossRef]

23. Naderi, R.; Rahmati, A. Phase-Shifted Carrier PWM Technique for General Cascaded Inverters. IEEE Trans. Ind. Electron. 2008, 23, 1257-1269. [CrossRef]

24. Peng, X.; He, X.; Han, P.; Guo, A.; Shu, Z.; Gao, S. Smooth Switching Technique for Voltage Balance Management Based on Three-Level Neutral Point Clamped Cascaded Rectifier. Energies 2016, 9, 803. [CrossRef]

25. Rabinovici, R.; Baimel, D.; Tomasik, J.; Zuckerberger, A. Thirteen-level cascaded H-bridge inverter operated by generic phase shifted pulse-width modulation. IET Power Electron. 2013, 6, 1516-1529. [CrossRef]

26. Townsend, C.D.; Summers, T.J.; Betz, R.E. Impact of Practical Issues on the Harmonic Performance of Phase-Shifted Modulation Strategies for a Cascaded H-Bridge StatCom. IEEE Trans. Ind. Electron. 2014, 61, 2655-2664. [CrossRef]

27. Lu, Z.G.; Zhao, L.L.; Zhu, W.P.; Wu, C.J.; Qin, Y.S. Research on cascaded three-phase-bridge multilevel converter based on CPS-PWM. IET Power Electron. 2013, 6, 1088-1099. [CrossRef]

28. Yao, W.; Lu, Z.; Hu, H. Carrier phase shift PWM techniques of three-level H-bridge cascaded multilevel inverter (in Chinese). Zhejiang Daxue Xuebao (Gongxue Ban) 2008, 42, 1330-1334.

29. Lau, W.H.; Zhou, B.; Chung, H.S.H. Compact analytical solutions for determining the spectral characteristics of multicarrier-based multilevel PWM. IEEE Trans. Circuits Syst. Regul. Pap. 2004, 51, 1577-1585. [CrossRef]

30. Reznikov, B.; Srndovic, M.; Familiant, Y.L.; Grandi, G.; Ruderman, A. Simple Time Averaging Current Quality Evaluation of a Single-Phase Multilevel PWM Inverter. IEEE Trans. Ind. Electron. 2016, 63, 3605-3615. [CrossRef]

31. McGrath, B.P.; Holmes, D.G. An analytical technique for the determination of spectral components of multilevel carrier-based PWM methods. IEEE Trans. Ind. Electron. 2002, 49, 847-857. [CrossRef]

32. Shu, Z.; Zhu, H.; He, X.; Ding, N.; Jing, Y. One-inductor-based auxiliary circuit for dc-link capacitor voltage equalisation of diode-clamped multilevel converter. IET Power Electron. 2013, 6, 1339-1349. [CrossRef]

33. Townsend, C.D.; Summers, T.J.; Betz, R.E. Phase-Shifted Carrier Modulation Techniques for Cascaded H-Bridge Multilevel Converters. IEEE Trans. Ind. Electron. 2015, 62, 6684-6696. [CrossRef]

(C) 2018 by the authors. Licensee MDPI, Basel, Switzerland. This article is an open access article distributed under the terms and conditions of the Creative Commons Attribution (CC BY) license (http://creativecommons.org/licenses/by/4.0/). 